\title{
Toxicity of Some Plant Oil Nanoemulsions to Black Cutworm, Agrotis ipsilon Hufnagel (Lepidoptera: Noctuidae)
}

\author{
Mohamed A.E. Elbadawy ${ }^{1}$, Mohamed M. Azab², Ali M. Shams El Din², and \\ Eman M.M. Radwan ${ }^{1}$ \\ ${ }^{1}$ Department of Insect Population Toxicology, Central Agricultural Pesticides Lab, Agricultural Research \\ Center, Dokki, Giza, Egypt. \\ mohamedelbadawy280@gmail.com (M.A.E.E.), \\ dr.eman.Radwan@gmail.com (E.M.M.R.) \\ ${ }^{2}$ Department of Plant Protection, Faculty of agricultural, Benha University, Qalyobia, Egypt, \\ azabmohamed@hotmail.com (M.M.A.), alishams@ consultant.com (A.M.S.E.D.) \\ Submitted: 04.02.2019 | Accepted: 02.07.2019 | Published: 1/9/2019
}

\begin{abstract}
The insecticidal activity of some botanical oils on the black cutworm, Agrotis ipsilon Hufnagel (Lepidoptera: Noctuidae) was evaluated in laboratory assays. Oils of jojoba, garlic, and pumpkin plants were prepared in the form of nanoemulsion. Second and fourth instars larvae were treated with original oils and their nanoemulsions via the leaf dipping technique. The results revealed that $5 \%$ nanoemulsion oils were significantly more effective than original forms. The average size of the nanoparticles of effective nanoemulsion oils was 185.4, 362.9, and. $281.5 \mathrm{~nm}$ for jojoba, garlic, and pumpkin, respectively. The obtained data indicated the nanoemulsion of jojoba oil was the most effective against 2nd and 4th instars larvae, causing $100 \%$ and $60 \%$ mortality after 2 days of the treatment at concentration of $5 \%$ for 2 nd and 4 th instars larvae, respectively. It was concluded that the formulated nanoemulsion of these botanical oils can be used as an effective alternative to commercial pesticide formulations to control A. ipsilon larvae.
\end{abstract}

Keywords : black cutworm; plant oils; bioassay nanoemulsion 